\title{
O heroísmo do presente
}

\author{
KATIA MURICY
}

RESUMO: Uma aproximação da história do presente de Michel Foucault da concepção de história de Walter Benjamin, a partir de suas análises sobre a visão de modernidade como construção do tempo na obra de Baudelaire.

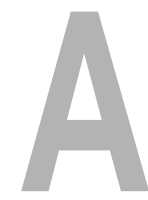

o contrário de Walter Benjamin, Michel Foucault escreveu muito pouco sobre Baudelaire. Mesmo alusões ao poeta são escassas em sua obra. Há uma afirmação breve, mas decisiva, que dá a Baudelaire uma importância semelhante a que concedera, em páginas generosas de As palavras e as coisas, a Mallarmé - este que, devolvendo às palavras sua densidade, fizera da poesia a expressão mais completa das inflexões contemporâneas à questão da linguagem. Formulada no espaço filosóficofilológico aberto por Nietzsche, esta questão inaugura para Foucault, o terreno próprio da modernidade. É em Baudelaire que Foucault encontra, em uma entrevista de 1983, um sentido preciso para o termo modernidade na França (Foucault, 1983). Um ano mais tarde, Foucault esclarece sua afirmação. Se Mallarmé configurara a linguagem como o grande tema da modernidade, com Baudelaire, nas reflexões de Foucault dos anos 80, é uma nova percepção de tempo que estabelece o próprio conceito de modernidade.

As pouco mais que duas páginas a que se restringem as considerações de Foucault sobre Baudelaire aparecem no artigo O que é o Iluminismo?, publicado em 1984, em The Foucault reader, editado por Paul Rabinow nos Estados Unidos. O artigo desenvolve um texto publicado em abril do mesmo ano na Magazine Littéraire ( $\mathrm{n}^{\circ}$ 207) que resume o curso de 1983 no Collège de France. Trata-se da leitura de Was ist Aufklärung?, resposta de Kant à questão proposta, em 1784, por um jornal berlinense. Este texto menor de

UNITERIMOS:

Foucault, Benjamin, Baudelaire, história, historia do presente, tempo, modernidade.

Professora do Departamento de Filosofia da PUC-RJ 
Kant sempre exerceu um grande fascínio sobre Foucault. Em 1978, encontrase a primeira referência a ele, na introdução escrita por Foucault à edição em língua inglesa do livro de Georges Canguilhem $O$ normal e o patológico, posteriormente editada em francês com o título La vie, l'expérience et la science (1985, p. 3-14). Ao menos nas duas últimas leituras que faz deste texto, Foucault, através de Kant, apresenta a sua própria concepção de vida filosófica. Na versão mais atual, recorre a Baudelaire para explicitá-la melhor. Minha hipótese é que Baudelaire pode ser uma lente sensível para o foco que Foucault quer jogar sobre Kant a fim de iluminar a sua própria concepção da filosofia. Penso também que, por esta inclusão de Baudelaire na explicitação da originalidade do vínculo que estabelece entre a história, filosofia e atualidade - isto que chama de uma ontologia do presente - se pode relacionar Foucault com Walter Benjamin que, também por uma análise de Baudelaire, estabelece um elo inusitado entre tradição e modernidade a partir de um conceito de tempo não linear. Nos dois autores, uma leitura muito particular de Kant é feita a partir de preocupações que ambos compartilham com o poeta. $\mathrm{O}$ artista moderno e o filósofo moderno encontram-se na mesma tarefa de pensar uma nova relação com o tempo - e, logo, com a tradição e a história - e consigo mesmo. Há certamente diferenças essenciais: entre outras, Baudelaire é um objeto de estudo exaustivo para Benjamin enquanto em Foucault, como indiquei, a presença do poeta é tênue e quase exclusivamente no texto de 1983 sobre Kant. Por outro lado, Benjamin define sua tarefa em Filosofia considerando Kant a partir do sistema, da primeira Crítica, enquanto Foucault toma para isto um texto de circunstância. Além disto, os estudos de Benjamin sobre Baudelaire são muitos anos posteriores ao seu texto sobre Kant. Apesar destas diferenças a visão de modernidade de Baudelaire não deixa de ser decisiva para a compreensão do projeto filosófico de ambos.

Apresentando o livro de Canguilhem, Foucault deriva a dignidade filosófica da história das ciências de seu compromisso com o tema, introduzido no século XVIII "sem dúvida de um modo um pouco subreptício e como que por acidente”, que, ao lado da indagação sobre a natureza, o fundamento e a legitimidade do pensamento racional, perguntava-se também - esta a novidade - sobre as relações do "momento presente" com a história, perguntavase sobre a atualidade. A partir daí a história passa a ser um problema decisivo para a filosofia já que "fazia-se da Aufklärung o momento em que a filosofia encontrava a possibilidade de se constituir como a figura determinante de uma época e em que esta época tornava-se a forma de realização desta filosofia" (Foucault, 1978, p. 5). Esta questão teria o seu símbolo no debate promovido pelo Berlinische Monatschrift em torno da pergunta Was ist Aufklärung?, respondida em ocasiões diferentes por Kant e por Mendelsohn. Para Foucault, da questão da Aufklärung derivariam duas tradições: uma alemã, outra francesa. Na Alemanha, a inflexão da questão foi o da reflexão histórica e política sobre a sociedade. Foucault relaciona nesta tradição os póshegelianos, Feuerbach, Marx, Nietzsche, Max Weber, a Escola de Frankfurt, 
Lukács. Na França, a questão filosófica da Aufklärung tomou a direção da história das ciências: Saint-Simon, Comte, mas também Koyré, Bachelard, Cavaillès e Canguilhem responderam de maneiras distintas à questão decisiva da Aufklärung. Interessante é que, neste texto de 1978, Foucault não está apresentando duas tendências opostas que prenunciassem os termos de sua análise de 1983, não está opondo uma analítica da verdade a uma ontologia do presente, mas indicando uma complementaridade entre a história das ciências francesas e a teoria crítica alemã. Em ambas “... trata-se de examinar ... uma razão cuja autonomia estrutural carrega consigo a história dos dogmatismos e dos despotismos - uma razão, por conseqüência, que só tem efeito de emancipação com a condição que consiga liberar-se de si própria” (Foucault, 1978, p. 7). No texto de 1978, a Aufklärung é um questionamento da razão como despotismo e como luz; ela está presente em nossa atualidade como indagação constante do Ocidente sobre as suas possibilidades hoje e sobre as liberdades que lhe são possíveis. Neste texto, Foucault não define o seu projeto filosófico a partir de uma opção entre as duas tradições que indica.

A consideração desta primeira referência ao texto de Kant de 1784 poderia esclarecer talvez as relações de Foucault com o filósofo, nuançando surpresas como a de Habermas que, sabe-se, encontra no artigo publicado em 1984 na revista francesa, a novidade de um outro Foucault que, ao invés de denunciar a vontade de saber que subjaz às analíticas da verdade, dá a esta vontade uma compreensão nova, a do impulso crítico a que identifica o seu próprio pensamento. Penso que, nas retomadas e modificações da sua leitura do texto de Kant, o que encontramos é um mesmo projeto de pensar criticamente o que chamará de os limites atuais do necessário - aquilo que determina a nossa maneira de dizer, de pensar e de agir - mas também, para além de Kant, a possibilidade de ultrapassar estes limites. Já a introdução de Baudelaire, na versão final, parece abrir, na leitura de Foucault do texto de Kant, uma nova perspectiva para o seu pensamento.

Na publicação do curso de 1983 na Magazine Littéraire, Foucault relaciona ao de 1784, o texto de Kant de 1798, O conflito das faculdades. Para Foucault, há aí um desdobramento da questão O que é o Iluminismo? em outra pergunta - O que é a Revolução?. No contexto de 1798, trata-se de um desdobramento da indagação de Kant sobre a existência de um progresso constante para o gênero humano. Kant não se contenta em pensar o progresso no horizonte de um movimento teleológico, mas quer, em um recorte no fluxo da história, encontrar um acontecimento que valeria como signo do progresso. Este acontecimento é a revolução. Mas Kant não procura o lado heróico, ativo da revolução. Não se trata do acontecimento por assim dizer solene, mas do acontecimento menos grandioso, menos perceptível da recepção dos que passivamente assistem os atores do drama. É, sabe-se, o entusiasmo dos espectadores que, para Kant, se torna signo de uma disposição moral da humanidade para o progresso. Não é o processo revolucionário que importa, mas a recep- 
ção da idéia de revolução pelos indivíduos que não são seus atores. Isto é, interessa a Kant "o que se passa na cabeça dos que não fazem (a revolução) ...” Para Foucault, as duas questões entrelaçadas - O que éo Iluminismo? e $O$ que é a revolução? - constituem a indagação de Kant sobre a atualidade e dão origem a uma tradição crítica diversa daquela constituída pela sua obra crítica sobre as possibilidades do conhecimento, ou seja, a tradição das filosofias analíticas da verdade. Esta nova postura crítica, nascida da indagação de Kant sobre a sua atualidade constitui o que Foucault chama de "ontologias do presente". Em uma versão que se distancia do prefácio de 1978, Foucault apresenta então as duas tradições em oposição: "pode-se optar por uma filosofia crítica que se apresentará como uma filosofia analítica da verdade em geral, ou bem pode-se optar por um pensamento crítico que tomará a forma de uma ontologia de nós próprios, de uma ontologia da atualidade" (Foucault, 1984b, p. 39). Evocando os mesmos autores que citara no prefácio de 1978 como pertencentes à tradição alemã, Foucault vincula a sua obra à tradição crítica pós-hegeliana.

Na edição americana The Foucault reader, onde se encontram as considerações sobre Baudelaire, há um desenvolvimento diverso das outras duas interpretações sobre o texto de Kant de 1784. Foucault não se refere aqui ao tema da revolução. Sua interpretação insiste sobre a questão da Aufklärung, enquanto decisão da vontade dos indivíduos, como atitude moderna, como um trabalho sobre si. Nesta nova leitura desaparece a consideração sobre a revolução e abre-se espaço para as considerações sobre Baudelaire. Esta nova disposição da análise pode ser vista como uma inflexão importante no pensamento de Foucault.

Foucault, "sem querer the dar um lugar exagerado na obra de Kant", resume aí a importância que tem para ele o texto de Kant. Para Foucault é a primeira vez que um filósofo liga tão necessariamente a obra a sua atualidade. Kant faz este elo ao considerar o projeto da crítica do conhecimento imprescindível para a atualidade, para a Aufklärung, porque a maioridade da razão requer o conhecimento dos limites do que se pode conhecer, do que é preciso fazer, do que é permitido esperar. "A Crítica [escreve Foucault] é o livro de bordo da maioridade da razão na Aufklärung; e inversamente, a Aufklärung é a idade da Crítica" (Foucault, 1984a, p. 38). Na resposta ao jornal berlinense, Kant liga ainda a sua obra à atualidade por uma nova reflexão sobre a história, feita em termos totalmente diversos da sua concepção anterior, que entendia a história pela finalidade interna do tempo e pela meta do processo. Aqui Kant entende a Aufklärung como passagem a um estado de maioridade, como um acontecimento diverso do processo histórico em geral, momento em que cada indivíduo é responsável pela construção da atualidade. Finalmente Kant vê, neste texto, uma integração do filósofo, de si próprio, no momento singular em que escreve a sua obra e para o qual a escreve. Resumindo as duas últimas formas, Foucault escreve: "A reflexão sobre o 'hoje' como diferença na história e como motivo para uma tarefa filosófica parti- 
cular me parece ser a novidade deste texto" (Foucault, 1984a, p. 38).

Esta leitura de Kant já remete a Baudelaire antes mesmo que Foucault o evoque. Para Baudelaire, o vínculo do artista com sua época é a condição de produção da obra de arte moderna. Este compromisso necessário com o presente determina uma relação especial da obra com o tempo e com a história. Determina uma vontade, uma vida moderna. Em resumo, o que interessa a Foucault é como Kant relaciona sua filosofia, à atualidade, à Aufklärung. Para Foucault, a modernidade não é apenas um período histórico, mas, antes de tudo, "um modo de relação com a atualidade", "uma escolha voluntária", uma "atitude de modernidade". Esta atitude de Kant, Foucault caracteriza como uma maneira nova de pensar, de sentir, de agir e de se conduzir. Sobretudo uma consciência de pertencer ao presente e, ao mesmo tempo, da necessidade de moldá-lo. É uma consciência do presente como diferença em relação ao passado. Quando Foucault distingue a tematização kantiana da relação entre a filosofia e o presente, indicando que a Aufklärung, para Kant, não é definida nem a partir de uma totalidade nem de um desenvolvimento futuro, quando nos põe diante de um Kant tão diverso do Kant de $A$ história universal do ponto de vista cosmopolita, o que quer é sublinhar a compreensão kantiana da Aufklärung como ato de vontade. A Aufklärung deve ser, segundo Kant, uma modificação na relação entre vontade, autoridade e uso da razão. De maneira, segundo Foucault, "quase negativa”, Kant caracteriza a Aufklärung como uma saída da menoridade. É por uma disposição da vontade que esta saída pode ocorrer; ela é uma tarefa, uma obrigação, um processo em desenvolvimento. Para Kant, o homem é responsável pelo seu estado de menoridade e para sair desse estado ele precisa fazer uma mudança pessoal, um trabalho sobre si mesmo. $\mathrm{O}$ aude sapere - $\mathrm{o}$ ousar saber kantiano - explicita a Aufklärung como "um ato de coragem a ser efetuado pessoalmente". A atitude de modernidade que Foucault encontra em Kant corresponde a ver na Aufklärung um processo, uma atualidade histórica da qual os homens fazem parte mas que só se produz por uma decisão deles: "É preciso pois considerar a Aufklärung como um processo do qual os homens fazem parte coletivamente e um ato de coragem a ser efetuado pessoalmente. São simultaneamente elementos e agentes do mesmo processo. Podem ser seus atores na medida que dele fazem parte; e ele só se produz na medida em que os homens decidem ser seus atores voluntários" (Foucault, 1984a, p. 35).

Em resumo, através do texto de Kant, Foucault apresenta a sua concepção da modernidade não como período histórico mas como atitude. Por atitude ele entende um modo de relação com respeito à atualidade; uma determinada escolha voluntária feita por indivíduos; uma maneira de pensar, sentir, agir e conduzir-se que demarca o pertencer a uma época e que é proposta como uma "tarefa". Para caracterizar esta atitude moderna, Foucault toma o exemplo "quase necessário" de Baudelaire, "reconhecidamente uma das consciências mais agudas da modernidade no século XIX". Baudelaire, que afirmava "vous n'avez pas le droit de mépriser le présent", via a modernidade 
como uma forma de relação com o presente e como uma forma de relação consigo mesmo, no espaço da arte.

A modernidade de Baudelaire, para Foucault, refere-se primeiramente a uma atitude em relação à percepção do tempo. A característica atribuída habitualmente à modernidade - a consciência da descontinuidade do tempo relacionada à ruptura com a tradição, a erupção da novidade e a experiência da fugacidade dos acontecimentos - não basta para se compreender a modernidade de Baudelaire. Se o poeta define a modernidade como "o transitório, o fugidio, o contingente”, a atitude moderna que Foucault encontra em Baudelaire é aquela que o leva a não simplesmente constatar e se contentar com esta apreensão da descontinuidade do tempo. É, ao contrário, uma tomada de posição que, de certo modo, se opõe à transitoriedade. Consiste em procurar, por uma decisão da vontade, construir uma eternidade muito particular. Este conceito de eterno não busca eleger uma atemporalidade, projetada no passado ou no futuro, mas em circunscrever-se no instante presente.

A modernidade de Baudelaire seria a de não aceitar o curso do tempo e por uma atitude voluntária, construí-lo, submetendo-o a este ato de vontade. É por esta decisão da vontade que Baudelaire irá encontrar o heróico. A modernidade de Baudelaire não seria apenas uma sensibilidade ao presente transitório, fugidio, mas uma decisão, uma atitude firme de heroificar o presente.

Foucault observa que a heroificação é irônica. Não se trata de uma sacralização do presente, do instante, para perpetuá-lo. Mas também não se trata, sobretudo, de arquivá-lo como curiosidade fugidia. Esta segunda atitude seria própria do flâneur que tem algo de veleidade na atitude de colecionador de lembranças que lhe permite fugir da atualidade, das circunstâncias. Nem sacralizar o instante, nem apanhá-lo como curiosidade A atitude do moderno é a busca da modernidade entendida por Baudelaire como "dégager de la mode ce qu'elle peut contenir de poétique dans l'historique”.

Foucault cita a conhecida crítica de Baudelaire aos pintores seus contemporâneos que representavam os personagens do século XIX vestidos com togas da Antiguidade por acharem as roupas modernas indignas de serem representadas. Mas Baudelaire não acha que basta substituir togas pelos ternos pretos. O pintor moderno deve, além de pintar os personagens com ternos pretos, mostrar esses trajes como "a vestimenta necessária da nossa época" e isto porque o preto das roupas revelaria em uma alegoria, o essencial luto, a relação obsessiva da nossa época com a morte.Constantin Guys não é, embora aparente, um flâneur. Ele é o que trabalha arduamente quando todos dormem, à noite - este tempo subtraído do fluxo produtivo capitalista - transfigurando o mundo, o real. Um duelo que não pretende anular este real mas estabelecer um jogo entre a verdade do real e o exercício da liberdade. Para Baudelaire, as coisas naturais tornam-se nos desenhos de Constantin Guys "mais que naturais", as coisas belas "mais que belas".

Foucault define a sua compreensão do trabalho do filósofo moder- 
no como semelhante ao do artista moderno de Baudelaire: "Pela atitude de modernidade, o alto valor do presente é indissociável do esforço furioso para imaginá-lo de forma diferente e para transformá-lo, não pela sua destruição mas pela captura do que ele é. A modernidade baudelairiana é um exercício onde a extrema atenção ao real é confrontada com a prática de uma liberdade que é, ao mesmo tempo, respeito e violação deste real" (Foucault, 1984a, p. 41). A atitude de modernidade estendida por Foucault a seu próprio pensamento não é, como não era para Baudelaire, um estado subjetivo. Para evitar este mal entendido, Foucault usa o termo ethos. Este ethos moderno é heróico na sua decisão de problematizar o presente e este heroísmo é necessariamente irônico. O aude sapere kantiano ganha, juntando-se à atitude de Baudelaire, a feição que permite não só reconhecer os limites do que na nossa atualidade se pode pensar, fazer e esperar, mas também ironizar esses limites: poder pensar, agir, sentir para além deles. $O$ presente, carregado de possibilidades, pode ser objeto de uma construção, o que permite uma mobilidade em suas relações com o passado. Parece-me que, neste aspecto, a afinidade com o pensamento de Benjamin é explícita.

Baudelaire concebia a modernidade como algo mais do que uma relação específica com o presente. Concebia-a também como uma forma de relação que se deve construir consigo mesmo. Esta forma moderna de relacionar-se consigo mesmo é o ascetismo. O eu moderno é, em consequiência mesmo da atitude de construção do tempo, também objeto de uma construção. Há em Baudelaire uma recusa em aceitar o eu por assim dizer natural que existe no fluxo dos momentos. Este esforço árduo de construção de si Baudelaire chama de dandismo. O ascetismo do dândi, "de seu corpo, de seu comportamento, de seus sentimentos e paixões, faz de sua existência uma obra de arte”. Foucault escreve, aludindo mais uma vez ao seu próprio projeto filosófico, "o homem moderno, para Baudelaire, não é o que parte para a descoberta de si mesmo, de seus segredos e de sua verdade escondida; é o que procura inventar-se a si próprio. Esta modernidade não "libera o ser próprio do homem"; ela o obriga à tarefa de se elaborar a si próprio” (Foucault, 1984a, p. 42). Foucault termina suas poucas páginas sobre Baudelaire observando que a heroificação do presente, o jogo da liberdade com o real, a elaboração ascética de si não tem lugar na sociedade ou na política, mas a atitude moderna só pode ser vivida "no que Baudelaire chama arte".

Como já indiquei acima, na última versão da leitura do texto de Kant de 1784 Foucault deixa de lado a pergunta sobre a Revolução, que em 1983 apontara como complementar àquela sobre a Aufkärung, para delinear o espaço da investigação filosófica moderna. É Baudelaire que dá seqüência à caracterização da atitude moderna. Paul Veyne comenta o quanto nos últimos meses de vida Foucault ocupou-se com a idéia de estilo de existência. Segundo Veyne: “ A moral grega está morta e Foucault considerava tão pouco desejável quanto impossível ressuscitá-la; mas um detalhe desta moral, a saber a idéia de um trabalho de si sobre si, lhe parecia suscetível de se 
retomar num sentido atual..." (Veyne, 1986, p. 939-940). O tema de estilo de existência fundamentaria em novas bases a autonomia do indivíduo abrindo a possibilidade de se pensar uma nova moral: “(...) O eu se tomando a si próprio como obra a realizar poderia sustentar uma moral que nem a tradição nem a razão conseguem mais sustentar: artista de si próprio, o eu gozaria desta autonomia indispensável à modernidade. (...) Enfim se o eu nos liberta da idéia que entre a moral e a sociedade. (...) existe um elo analítico ou necessário, então não há mais necessidade de esperar a Revolução para começar a nos atualizar: o eu é a nova possibilidade estratégica" (Veyne, 1986, p. 939-940).

Em um artigo de 1918, Sobre a filosofia futura, Walter Benjamin apresenta suas reflexões sobre quais seriam as tarefas da filosofia (Benjamin, 1971, p.102). Como Foucault, é em Kant que Benjamin encontra a sua tradição. Ou, melhor, também é propondo uma leitura radicalmente seletiva de Kant que Benjamin cria a sua tradição. Seu ponto de partida é a pergunta sobre a relação que a filosofia vindoura poderia ter com o sistema kantiano: "Para a filosofia futura é da maior importância reconhecer e separar os elementos do pensamento kantiano que devem ser assumidos e mantidos, os que devem ser remanejados e os que devem ser rejeitados" (Benjamin, 1971, p. 100). Ainda que incontornável em sua importância, há uma insuficiência básica na filosofia de Kant: a fundação do conhecimento sobre uma "realidade de nível inferior, talvez o mais inferior nível", ou seja um conceito de experiência limitado pela visão de mundo da Aufklärung. Este "conceito inferior de experiência", reduzido "ao ponto zero, ao mínimo de significação" é tirado das ciências naturais ou, na melhor das hipóteses, "de uma certa física newtoniana". Assim limitado pela noção de experiência que, pagando tributo à sua época, tiranicamente deveria assumir, Kant só teria dado uma solução satisfatória a um dos dois aspectos da teoria do conhecimento: aquele referente a certeza do conhecimento que permanece, o lado "intemporal do saber". O segundo aspecto - o da experiência temporal e de sua certeza teria sido negligenciado por Kant "na sua estrutura total como uma experiência singularmente temporal". Atento a esta dimensão temporal, preocupado com a redução da noção de tempo ao modelo biológico, Benjamin irá encontrar no modelo estético a riqueza de uma concepção de temporalidade que lhe permitirá construir sua epistemologia e seu conceito de história. Apenas como indicação da perspectiva que orientará sua obra, cito uma carta a Florens Rang, de 9 de dezembro de 1923, na qual, rejeitando a concepção tradicional de história da arte ou de história da filosofia, difere a temporalidade das obras de arte de uma temporalidade finalmente biológica que vinha prevalecendo nestas disciplinas. Ainda nesta carta, propõe uma mesma temporalidade intensiva para a interpretação das obras de arte e das idéias: "A reflexão que me ocupa diz respeito à relação das obras de arte com a vida histórica. Tenho agora como certo que não há história da arte. (...) Do ponto de vista do que lhe é essencial, ela [a obra de arte] é a-histórica. [Obras de arte] não têm 
nada que as ligue umas às outras ao mesmo tempo de modo extensivo e a título essencial. $O$ elo essencial das obras de arte entre si se dá de modo intensivo. Nisto as obras de arte são análogas aos sistemas filosóficos, o que se chama de história da filosofia sendo ou bem uma história de dogmas ou de filósofos, desprovida de interesse, ou então a história de problemas na medida em que está a todo momento ameaçada de perder contato como contexto histórico e de voltar-se à interpretação intemporal, intensiva. A historicidade específica das obras de arte é também deste tipo, que não se descobre em uma história da arte mas somente em uma interpretação. Uma interpretação, na verdade, faz jorrar conexões que são atemporais, sem serem por isto desprovidas de importância histórica" (Benjamin, 1979, p. 293). Observo que a noção de interpretação em Benjamin difere da concepção hermenêutica tradicional, que confere a categoria de sujeito um papel essencial, na medida em que justamente descarta os temas reflexivos da filosofia moderna. É a partir basicamente desta compreensão de temporalidade que Benjamin irá repensar os vínculos da modernidade com a tradição e construir o seu conceito de história. Seus estudos da década de 30 sobre Baudelaire constituem, sem dúvida, uma peça importante para estas elaborações.

Já foi observado que, através de Baudelaire, Walter Benjamin não cessa de falar de si próprio. Seus clássicos ensaios sobre o poeta respondem a uma exigência de pensamento muito próxima a que Foucault se faz nos seus artigos dos 80 sobre Kant. Benjamin também considera tarefa filosófica tomar a história como objeto de construção a partir de uma concepção de tempo voltada para um presente em relação transformadora com o passado. Isto é, um presente que rompe como as falsas continuidades da tradição e estabelece a sua própria origem e um novo elo com o passado, criando, por assim dizer, a sua tradição. Problematizar o presente e a tradição para ambos é receber a herança iluminista em uma radical fidelidade à dimensão crítica.

Como a de Foucault, a leitura de Benjamin procura uma teoria da modernidade em Baudelaire. Mas, diversamente, considera os ensaios estéticos menos importantes para isto. Para ele, "a teoria da arte moderna é, na visão baudelairiana da modernidade o ponto mais fraco...”. O que conduz Benjamin a esta conclusão é não ter encontrado na teoria da modernidade dos ensaios de Baudelaire a relação decisiva entre a modernidade e a antigüidade que, no entanto, o poeta constrói na sua lírica: “...nenhuma das reflexões estéticas (...) expõe a modernidade em sua interpenetração com a antigüidade como ocorre em certos trechos de As flores do mal” (Benjamin, 1989a, p. 81). O tema da heroificação como atitude moderna - explicitado por Baudelaire no axioma de sua teoria da modernidade, "O herói é o verdadeiro objeto da modernidade" - aparece de forma mais rica na poesia, vinculado a uma concepção da relação entre o passado e o presente, entre antigüidade e atualidade, que determina a sua apreensão do moderno. Embora com esta diferença, a valorização da percepção da modernidade em Baudelaire, pela sua proposta de construção do tempo, é a mesma que, como indiquei acima, faz 
Foucault. O presente não é para o poeta, observa Benjamin, apenas um tempo fugidio de transição, mas uma construção que determina novas relações com o passado. O modelo de temporalidade é o das obras de arte autênticas que, ao surgirem, determinam uma ruptura que inaugura a sua própria tradição. Esta tematização está no cerne da concepção de origem em Benjamin e muito próximo da genealogia de Foucault se lermos, por exemplo, o artigo Nietzsche, a genealogia e a história como explicitação de suas próprias preocupações a respeito da história (Foucault, 1975a, p. 15-37).

O heroísmo em Baudelaire consiste em propor à poesia, à arte, fazer da modernidade, um dia, algo de clássico. Walter Benjamin sugere uma aproximação de Baudelaire com o Nietzsche de $O$ nascimento da tragédia pela consideração que o poeta faz de Wagner na frase que, segundo Benjamin, contém em essência a sua teoria da arte moderna, entendida na articulação antigüidade/modernidade: "Se Wagner, na escolha de seus temas e no seu proceder dramático, se aproxima da antigüidade, torna-se, graças à sua força de expressão apaixonada, o representante mais importante da modernidade" (Benjamin, 1989a, p. 80). O herói moderno, em Baudelaire, aparece com nitidez para Benjamin em um poema como As queixas de Ícaro, construído a partir da percepção não apenas do declínio do herói trágico clássico, que " teve de ceder espaço ao herói moderno, cujos feitos são relatados por La Gazette des Tribunaux” (p.79), mas também de que o herói moderno se constitui já sob o signo do declínio. A heroificação é, como também observa Foucault, irônica. O clássico moderno é precário: a modernidade quebra a tradição e, ao mesmo tempo, problematiza-se como tradição virtual. Para Benjamin, esta é a grande indagação de Baudelaire sobre a sua atualidade: "assim que vê seus direitos conquistados, a modernidade expira. Então será posta à prova. Após sua extinção, verificar-se-á se algum dia pode ou não tornar-se antigüidade” (Benjamin, 1989a, p. 80). Poder ser um dia lido como um autor antigo não era para Baudelaire um problema simples. Supunha um compromisso de construção de sua atualidade como heróica: "que a modernidade mereça um dia se tornar antigüidade" era o imperativo que, na leitura de Benjamin, elucida a compreensão da arte em Baudelaire.

O que Benjamin enfatiza, a serviço da sua teoria da alegoria, é como a beleza moderna, ligada à busca do novo, está paradoxalmente ligada à morte, à destruição do tempo. A cidade grande é o cenário desta morte. A análise, neste aspecto, se refere, entre muitos outros, ao mesmo texto de Baudelaire considerado por Foucault, sobre a roupa, "esse invólucro do herói moderno" que, convenientemente preta, alcança uma beleza política - já que nos torna todos democraticamente iguais - mas também uma beleza poética - já que "todos celebramos algum enterro". É em As flores do mal que, sem que constituam um tema explícito, a multidão e a grande cidade desenham a modernidade. A existência desta nova experiência urbana é a condição de possibilidade da lírica de Baudelaire. Mas a cidade, para Baudelaire, é, antes de tudo, uma alegoria da morte, do efêmero, do transitório. É nos Tableaux 
parisiens que Paris aparece na sua fragilidade: a cidade moderna como ruína antiga, como mimese da morte. Benjamin quer demonstrar como a concepção de modernidade em Baudelaire se dá sob o signo da precariedade, de uma apreensão do tempo em sua dimensão vertiginosa do instante. Assim, a urbanização de Haussmann o fazia ver Paris sempre em ruínas: "La forme d'une ville / Change plus vite, hélas! que le coeur d'un mortel”. A modernidade, identificada às cidades, é o vertiginoso passar, a mudança como regra permanente, as ruínas do há pouco novo. A leitura que Benjamin faz do conceito de modernidade em Baudelaire indica como esta, em sua precariedade, paradoxalmente cita a antigüidade, isto é, indica como o poeta sugere uma relação de simultaneidade entre elas, modificando-se assim, em sua percepção, a cronologia continuísta habitual.

É tematizando a relação modernidade/antigüidade em Baudelaire que Benjamin introduz o tema da forma alegórica, central para a compreensão da obra do poeta e da sua própria. No seu livro sobre o drama barroco alemão, escreveu que "a alegoria se instala mais duravelmente onde o efêmero e o eterno coexistem mais intimamente” (Benjamin, 1984, p. 247). Para Benjamin, o mundo de Baudelaire - o mundo capitalista - assemelha-se ao mundo barroco. Também há uma perda dos sentidos: é a época dos sujeitos e dos objetos transformados em mercadorias. O poeta já não encontra nas palavras o seu sentido habitual: a lírica tradicional caduca. São outras as palavras, as imagens usadas pelo poeta lírico moderno. Mas também é outra a sua percepção, os seus sentidos, as suas paixões. Se ressurgem as condições de articulação do efêmero com o eterno, como no período barroco, há uma nova função da visão alegórica no século XIX. É pela alegoria que Baudelaire põe a modernidade à distância. O spleen transforma todo presente em antigüidade, em realidade frágil da qual, no próximo instante, só subsistem as ruínas. As águas-fortes de Meryon, tão admiradas por Baudelaire, mostram Paris simultaneamente em ruínas, em escombros, e em construção. Encarnam o caráter alegórico da modernidade face à experiência da transitoriedade, da morte. Esta concepção de tempo que estabelece a simultaneidade do passado e do presente é capital para Benjamin. Na seção sobre a teoria do conhecimento, do livro sobre as Passagens, definindo a sua noção de imagem dialética escreve: "Não se deve dizer que o passado ilumina o presente ou que o presente ilumina o passado. Uma imagem, ao contrário, é onde o Antigo encontra o Agora em um raio para formar uma constelação. Em outras palavras, a imagem é a dialética parada. Porque, enquanto que a relação do presente com o passado é puramente temporal, contínua, a relação do Antigo com o Agora é presente e dialética: não é algo que se escoe, mas uma imagem descontínua. Somente as imagens dialéticas são imagens autênticas (...) e o lugar onde são encontradas é a linguagem” (Benjamin, 1989b, N2,a3, p. 478479). Baudelaire é o primeiro a usar na lírica palavras não só de proveniência prosaica, mas também urbana. Benjamin resume o seu estilo na fórmula de Claudel: “Baudelaire (...) teria unido o estilo literário de Racine ao de um 
jornalista do Segundo Império" (Benjamin, 1989a, p. 97). Neste novo vocabulário lírico "de súbito e sem nenhuma preparação, aparece uma alegoria... Sua técnica é a do putsch” (p. 97). Para Benjamin, há em Baudelaire a refletida elaboração da experiência poética a partir da experiência propriamente moderna do choque. Há um "plano de composição": "a produção poética de Baudelaire está associada a uma missão. (...) Sua obra não só se permite caracterizar como histórica, da mesma forma que qualquer outra, mas também pretendia ser e se entendia como tal" (Benjamin, 1989a, p. 110).

Esta construção do eu lírico a partir de uma acurada visão de seu presente; a modernidade entendida não só como percepção de descontinuidades mas como uma construção do tempo que estabelece novas relações com o presente e com o passado - a heroificação do presente - faz de Baudelaire um sugestivo ponto de interseção entre o pensamento de Foucault e o de Benjamin. Nas noções de jetztzeite de imagem dialética, que fundamentam as teses de Benjamin sobre o conceito de história, encontra-se a leitura dessa modernidade de Baudelaire conectada a uma antigüidade, como ela construída no espaço da linguagem. Enfatizando a atitude de insubmissão ao tempo linear como característica da modernidade recriada por Baudelaire, Foucault situa o seu projeto filosófico como uma insubmissão, ou seja, uma transgressão aos limites da tradição e do presente - isto a que chama de "respeito $e$ violação do real" no poeta. Baudelaire permite, assim, esclarecer algumas afinidades promissoras entre a concepção de história de Benjamin e o projeto genealógico de Foucault.

O pressuposto metodológico de uma visibilidade da história aproxima as concepções de Benjamin e de Foucault. Foucault, em seu artigo sobre Nietzsche, compreende a genealogia como o método que permite ver a história a partir de um ângulo estratégico. Para ele, a dimensão essencial que os historiadores tradicionais supõem escondida por trás dos fatos históricos é diretamente visível quando posta em evidência pelo genealogista. Benjamin quer "mostrar", quer "ensinar a ver": "Educar em nós o elemento criador de imagens para ensiná-lo a ver, de maneira estereoscópica e dimensional, na profundeza das sombras históricas.(...) Não tenho nada a dizer. Somente a mostrar" (Benjamin, 1989, N1a,8).

Não se trata, para Foucault ou para Benjamin, de ver, na multiplicidade dispersiva dos acontecimentos, a linha contínua em direção à meta que dotaria a história de um sentido. A genealogia quer "marcar a singularidade dos acontecimentos, longe de toda a finalidade monótona". Para Benjamin, o historiador deve ser "suficientemente viril para fazer saltar pelos ares o continuum da história" ${ }^{1}$. O genealogista e o "historiador viril" vêem descontinuidades onde a história tradicional encontra uma evolução contínua. $\mathrm{O}$ genealogista quer, escreve Foucault, "manter o que se passou na dispersão

Sobre o conceito de história ver tese 16 (Benjamin, 1985, p. 231). que lhe é própria” (Foucault, 1975, p. 21). Esta preocupação com insignificâncias históricas é também a do historiador viril de Benjamin, que pretende "descobrir na análise do pequeno momento singular o cristal do aconteci- 
mento total” (Benjamin, 1989b, N2,6). Ambos vêem, na história, violência e dominação e não o progresso da razão: "A peça representada nesse teatro sem lugar é sempre a mesma: é aquela que repetem indefinidamente os dominadores e os dominados. (...) A humanidade não progride lentamente, de combate em combate, até uma reciprocidade universal (...) ela instala cada uma de suas violências em um sistema de regras, e prossegue assim de dominação em dominação" (Foucault, 1975a, p. 24-25). Para Benjamin, a história é também "o cortejo triunfal" da violência dos dominadores, um “monumento à barbárie”, uma “catástrofe única” (cf. Benjamin, 1985).

Como Benjamin, Foucault é pouco ortodoxo em relação à historiografia. Ambos propõem escrever a história a partir da atualidade. Foucault quer "fazer a história do passado nos termos do presente", ou, em outras palavras, "fazer a história do presente" (Foucault, 1975b, p. 35). Benjamin quer "fundar a história passada na atualidade". Fazer a "história do presente" não significa, para eles, interpretar o presente a partir da história passada a fim de estabelecer uma continuidade entre este passado e as suas formas atuais de sobrevivência. Tampouco em interpretar o passado, dando-lhe novo sentido a partir de questões contemporâneas. A concepção de presente, para Foucault, é eminentemente crítica, requer um diagnóstico da atualidade e evita estabelecer continuidades. O diagnóstico é fruto de uma construção do presente. Assim, a noção de dispositivo, entendida como o conjunto de todas as práticas discursivas e não-discursivas de uma época, irá estabelecer uma relação do presente com o passado sem continuidades e sem finalismos. Esta noção supõe que, como Baudelaire no espaço da arte, Foucault construa, no espaço da história, a sua atualidade e também uma relação nova entre esta e o passado. Para Benjamin a perspectiva construtivista é indispensável para a historiografia: "a história é objeto de uma construção cujo lugar não é o tempo homogêneo e vazio, mas um tempo saturado de agoras" (Benjamin, 1985, tese 14). O agora é o presente do historiador no momento em que ele escreve a história. Passado e presente são, para o historiador, objetos de construção, arrancados do fluxo de um “tempo vazio e homogêneo" (Benjamin, 1985, tese 13). Considero que - como construção de novas relações com o tempo, como valorização e proposta de transformação do presente - a história é, para estes autores, uma certa forma de heroificação do presente, no sentido peculiar que Baudelaire deu ao termo heróico. 


\section{UNITERIMS:}

Foucault, Benjamin, Baudelaire, history, history of the present, time, modernity.
MURICY, Katia. The heroism of the present. Tempo Social; Rev. Sociol. USP, S. Paulo, 7(1-2): 31-44, october 1995.

ABSTRACT: An approach between Michel Foucault's history of the present and Walter Benjamin's conception of history, based on his analyses about the vision of modernity as a construction of time in Baudelaire's work.

\section{REFERÊNCIASBIBLIOGRÁFICAS}

Benjamin, Walter. (1971) Mythe et Violence. Paris, Denoël. . (1979) Correspondance. Vol. I, 1910-1928. Paris, AubierMontaigne.

. (1984) Origem do drama barroco alemão. Trad Sérgio Paulo Rouanet. São Paulo, Editora Brasiliense.

. (1985) Sobre o conceito de história.In: Obras escolhidas. Vol. I. Trad. Sérgio Paulo Rouanet. São Paulo, Editora Brasiliense.

. (1989a) Paris do Segundo Império. In: . Obras Escolhidas. Vol. III, Trad. J.C. Martins Barbosa e H. Alves Baptista. São Paulo, Editora Brasiliense.

. (1989b) Réflexions théoriques sur la connaissance, Paris capitale du XIX siècle - Le livre des passages. Trad. Jean Lacoste. Paris, Les Éditions du Cerf.

Foucault, Michel. (1975a) Microfísica do poder. Editora Graal, Rio de Janeiro.

. (1975b) Surveiller et punir. Naissance de la prison. Paris, Gallimard.

. (1978) Introdução. In: CANGUILHEM, Georges. O normal e o patológico. Boston, Reidel.

. (1983) Entrevista. Structuralism and pos-structuralism, Paris, Vol. $\mathrm{XVI}, \mathrm{n}^{\circ} 55$.

. (1984) O que é o iluminismo?. In: Rabinow, Paul. The Foucault reader. New York, Pantheon Books.

. (1984b) O que é iluminismo? Curso inédito realizado no Collège de France em 1983. Magazine Littéraire, nº 207, avril.

. (1985) La vie, l'expérience et la science. Revue de Métaphysique et de Morale, $\mathrm{n}^{\circ}$ 1, jan/mars: 3-14.

Veyne. (1986) Le dernier Foucault et sa morale. Critique, Paris, Édition de Minuit, n 471-472. 